\title{
حوكمة صناديق الثروة السيادية وشفافية أعمالها
}

\section{العابل ريمة العابة \\ كلية العلوم الاقتصادية

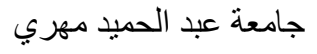 \\ قسنطينة}

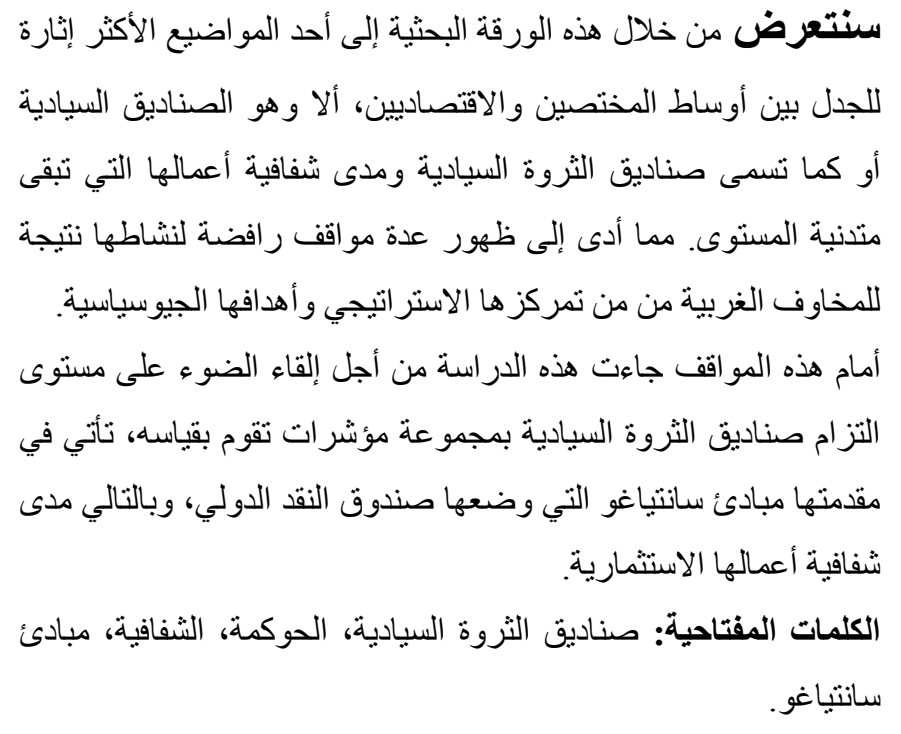

\section{Abstract :}

We elaborate in this paper to one of the most disputable subjects between the specialists and economists, which is the "Sovereign Wealth Funds (SWF)" and the level of them transparency which is qualified very low. The thing that results so many views refusing their activities consequently to the occidental fears from the strategically concentration and the geopolitical objectives of the SWF.

This study aims to demonstrate the level of the commitment of the sovereign wealth funds according to set of indices which measures their transparency and governance, starting by "The Principals of Santiago" put by the Monetary Fund.

Key words: Sovereign Wealth Funds, Governance, Transparency, The Principals of Santiago

$$
\text { 2016 جامعة الإخوة منتوري قسنطينة، الجز ائر (C) }
$$




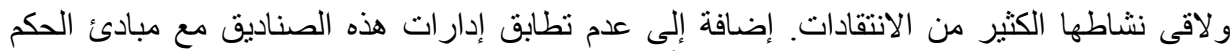

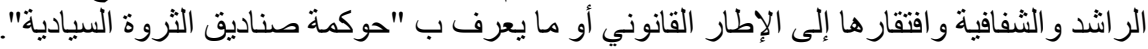

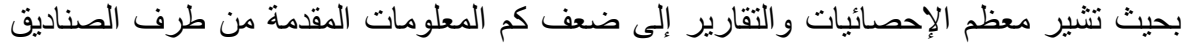

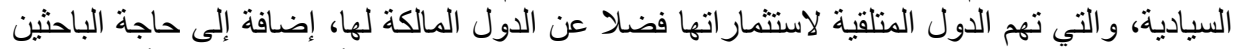

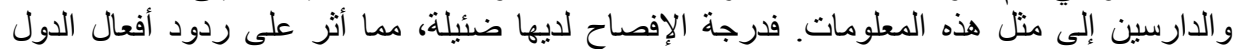

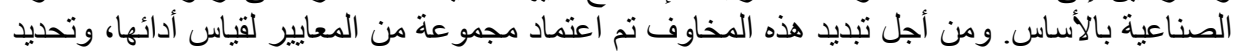

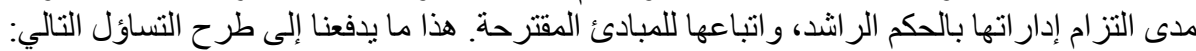

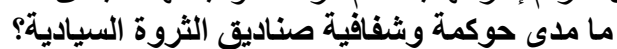
وتأتي تحت هذا التساؤل مجمو عنة من الأسئلة الفر عية:

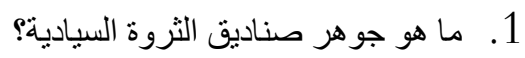
2.

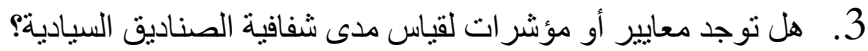

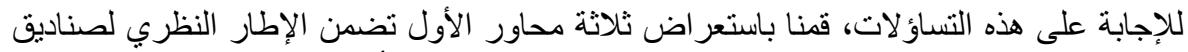

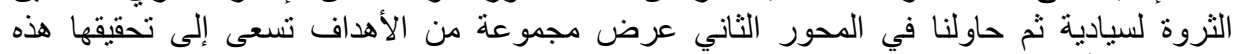

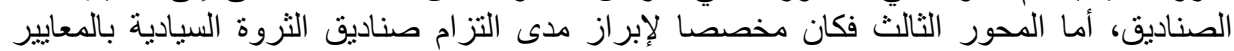

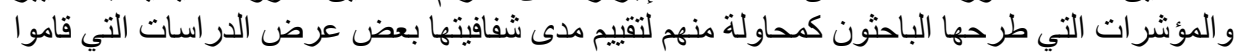

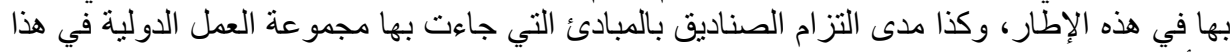

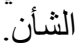

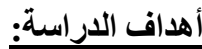

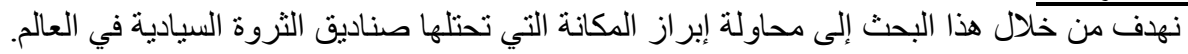

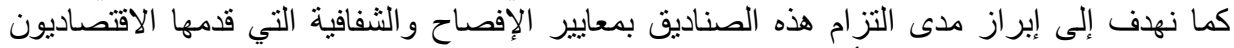
نتيجة للمخاوف الغربية عقب الأزمة العالمية في 2007. منهج الاراسة:

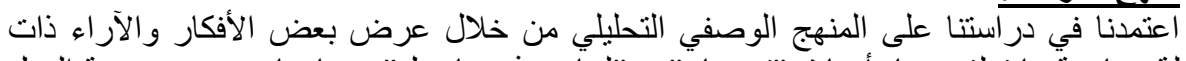

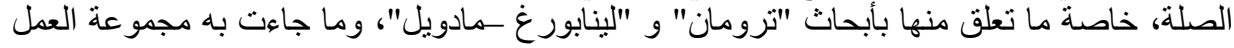

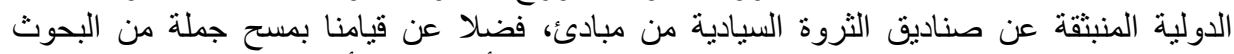

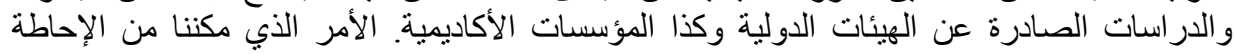

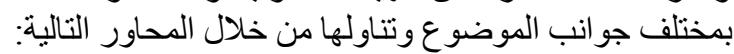

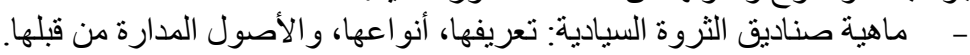

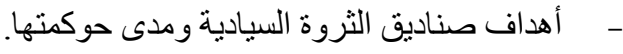
مادويل.

\section{المحور الأول: صناديق الثروة السيادية}

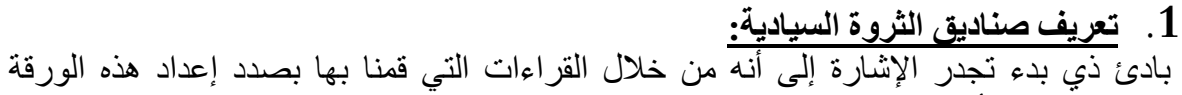

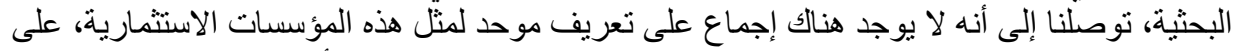

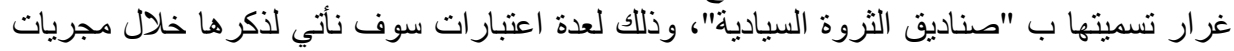

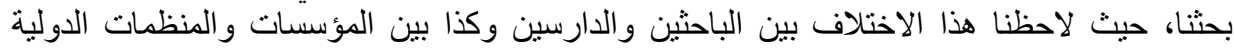

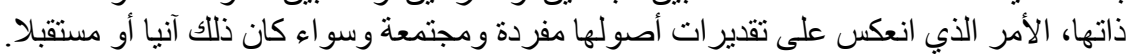

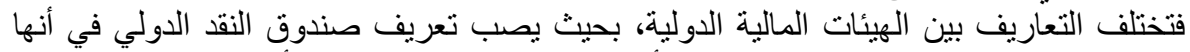
"صناديق للاستثمار تملكها الحكومة، تحتفظ بالأصول وتنتولى إدارتها لتحقيق أهداف مالية، مستخدمة لئل 
في ذلك استر اتيجيات استثمارية تتضمن الاستثمار في الأصول المالية الأجنيبة، وتتسم صناديق الثروة

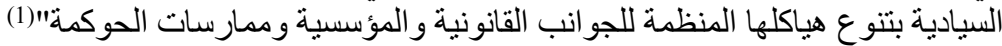

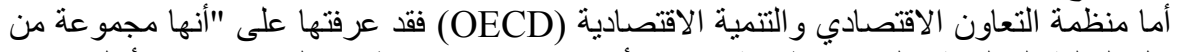

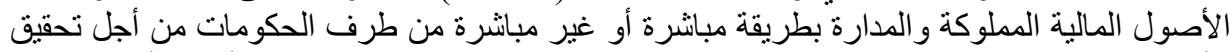

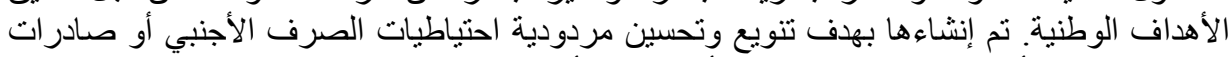

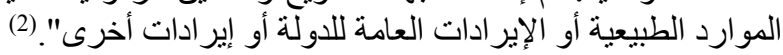

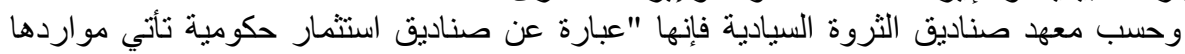

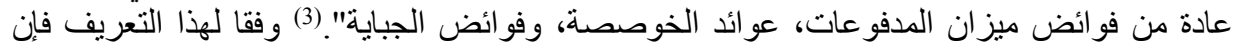

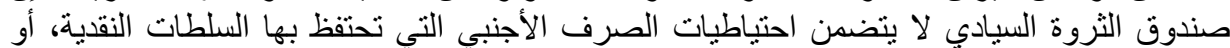

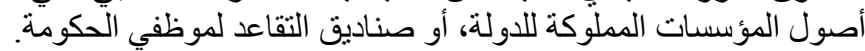

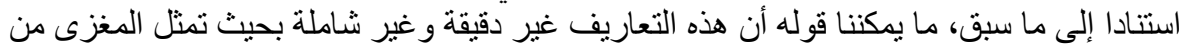

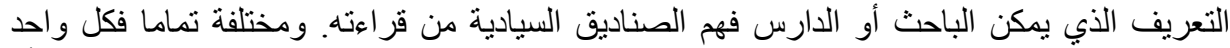
يعرفها من جانب فقط لا غير، فتعريف يركز على مواردها وآخر يقدمها من اتجاهاتها الاستثمارية أو الو أهدافها.

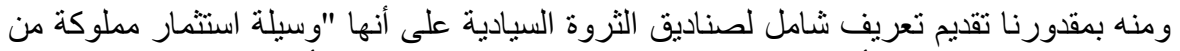

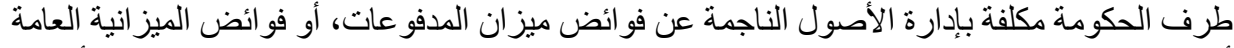

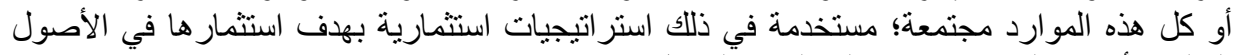

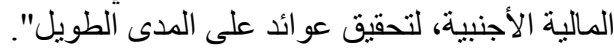
2. 2 نشأة صناديق الثروة السيادية:

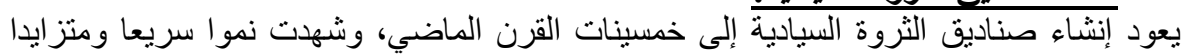

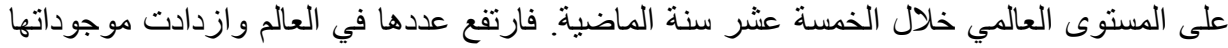

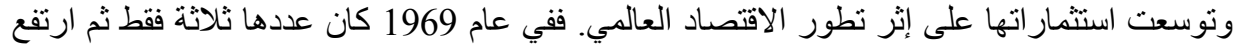

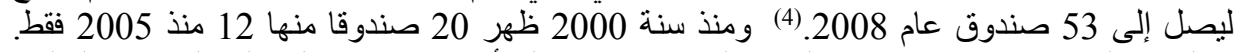

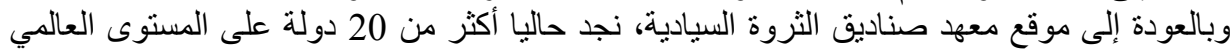

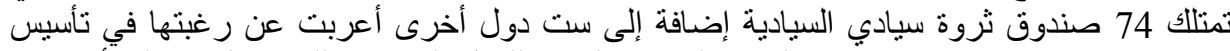

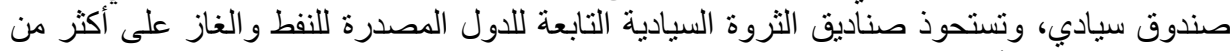

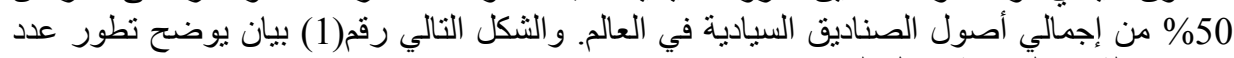
صناديق الثروة السيادية خلال الفترة 1950-2015.

\section{الثكل رقم(1): تطور عدد صناديق الثروة السيادية}

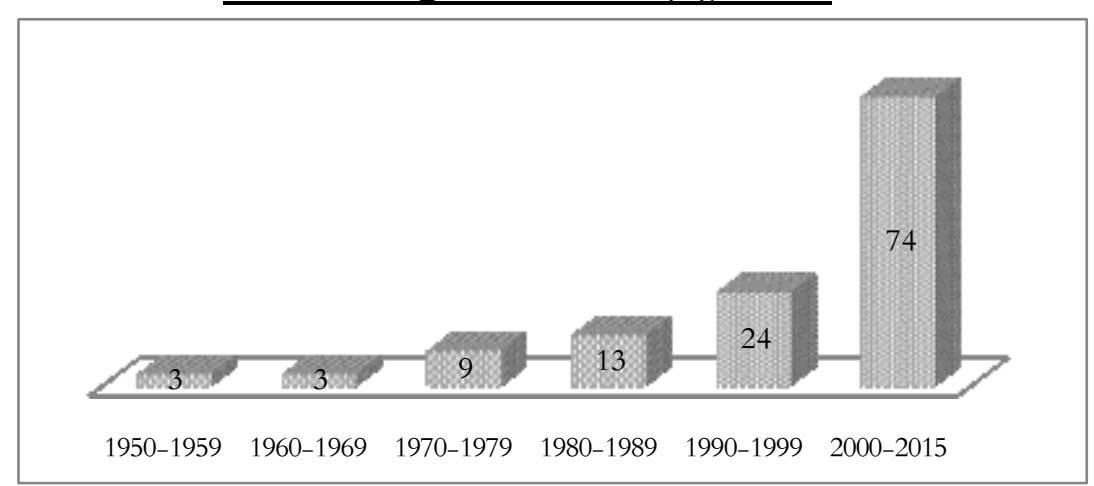


Source:http://fr.wikipedia.org/wiki/Fonds_souverain\#/media/File:Nb_fonds_so uverains monde.jpg

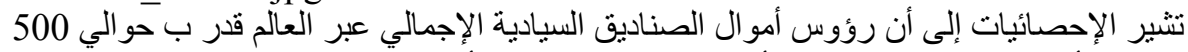

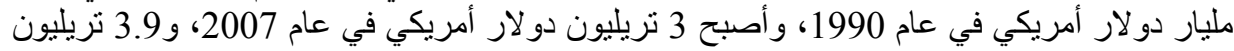

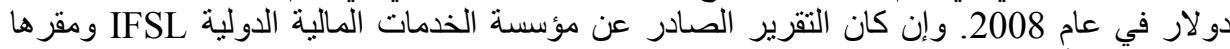

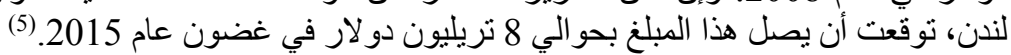

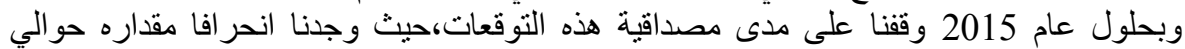

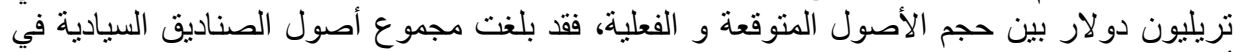

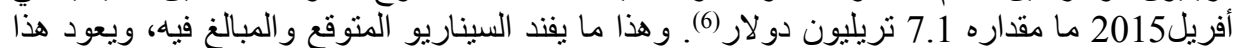

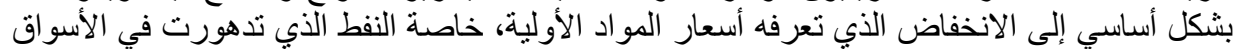

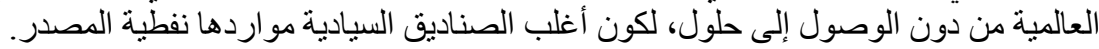
3. أهم صناديق الثروة السبادية في العالم:

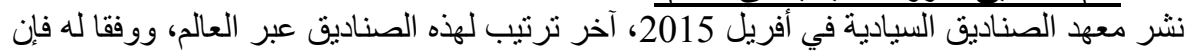

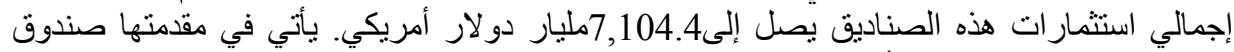

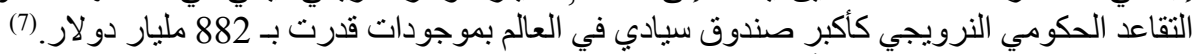

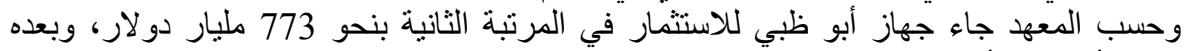

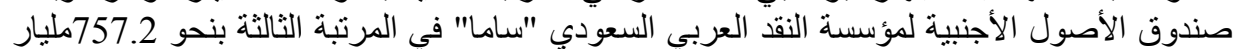

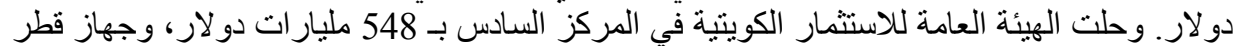

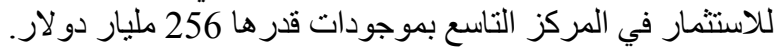
و الجدول رقم (2) يوضح أهم صناديق الثروة السيادية في العالم مع تاريخ تأسيسها، وتقديرات

الجدول رقم(2): أهم صناديق الثروة السيادية المتواجدة في العالم *الوحدة:(مليار دولار ). أصولها.

\begin{tabular}{|c|c|c|c|c|}
\hline مصدر التمويل & الأصول & تاريخ & الصندوق السيادي & البلد البل \\
\hline مو اد أولية (نفط) & 548 & 1953 & هيئة الاستثمار الكويتية & الكويت \\
\hline مو اد أولية (نفط) & 757.2 & غير & شركات قابضة عمومية & المعلكة العربية \\
\hline احتياطي الصرف & 177 & 1974 & تبماسك & سنغافورة \\
\hline مو اد أولية (نفط) & 773 & 1976 & هيئة الاستثمار أبو ظبي & أبو ظبي \\
\hline مو اد أولية (نفط) & 52.8 & 1976 & صندوق ألاسكا الدائم & الو.م.أ \\
\hline مو اد أولية (نفط) & 17.5 & 1976 & AHSTF & كندا \\
\hline احتياطي الصرف & 320 & 1981 & شركة الاستثمار الحكومية & سنغافورة \\
\hline مو اد أولية (نفط) & 40 & 1983 & وكالة الاستتمار لبروناي & بروناي \\
\hline
\end{tabular}


حوكمة صناديق الثروة السيادية وشفافية أعمالها

\begin{tabular}{|c|c|c|c|c|}
\hline مو اد أولية (نفط) & 882 & 1990 & صندوق المعانثات الحكومي & النرويج \\
\hline مو اد أولية (نفط) & 37.3 & 1999 & صندوق النفط الحكومي & أذربيجان \\
\hline احتباطي الصرف & 95 & 1998 & صندوق المستقبل الأستر الي & أستراليا \\
\hline احتباطي الصرف & 236 & 2000 & $\begin{array}{r}\text { الصندوق الوطني للضمان } \\
\text { الاجتماعي }\end{array}$ & الصين \\
\hline 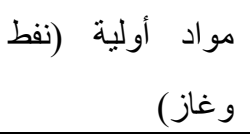 & 77.2 & 2000 & صندوق ضبط المو ارد & الجزائر \\
\hline مو اد أولية (نفط) & 77 & 2000 & $\begin{array}{r}\text { Khazanah Nasional } \\
\text { KNF }\end{array}$ & كازاخستان \\
\hline احتياطي الصرف & 27.4 & 2001 & 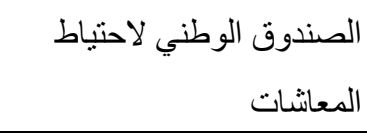 & ايرلندا \\
\hline مو اد أولية (نفط) & 66.3 & 2002 & شركة مبادلة للتنمية الدولية & أبو ظبي \\
\hline 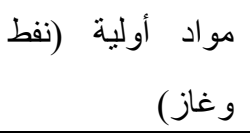 & 256 & 2005 & جهاز قطر للاستثمار & قطر \\
\hline مو اد أولية (نفط) & 66 & 2006 & هيئة الاستثمار الليبية & ليبيا \\
\hline احتياطي الصرف & 95 & 2006 & لأستر اليا & أستر اليا \\
\hline احتياطي الصرف & 84.7 & 2006 & شركة الاستثمار الحكومية & كوريا الجنوبية \\
\hline احتياطي الصرف & 652.7 & 2007 & شركة استثمار الصين & الصين \\
\hline مو اد أولية (نحاس) & 15.2 & 2007 & الاقتصادي و الاجتماعي الاستقرار & الثيلي \\
\hline مو اد أولية (نفط) & 88.9 & 2008 & صندوق الاحتياط & روسيا \\
\hline احتياطي الصرف & 79.9 & 2008 & صندوق الرفاه الوطني & روسيا \\
\hline مو اد أولية (نفط) & 77.5 & 2008 & الصندوق الوطني لكاز اخستان & كازاخستان \\
\hline احتياطي الصرف & 25.5 & 2008 & صندوق الاستثمار & فرنسا \\
\hline
\end{tabular}




\begin{tabular}{|c|c|c|c|c|}
\hline & & & الاستر اتيجي & \\
\hline 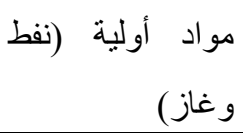 & 62 & 2011 & 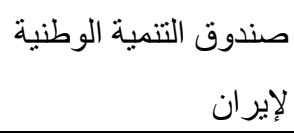 & إيران \\
\hline متنو عة & $1,417.3$ & - & 47 & صناديق سيادية أخرى \\
\hline \multirow[t]{2}{*}{ - } & $4,287.2$ & - & - & صناديق الثروة \\
\hline & $2,817.2$ & - & - & أخرى السيادية من مصادر \\
\hline - & $7,104.4$ & - & 74 & المجموع الكلي \\
\hline
\end{tabular}

Source: Fund Rankings, Wealth fund Institute,

“www.swfinstitute.org/fund-rankings/" Avril2015.

$$
\text { المحور الثانى: أنواع صناديق الثروة السيادية وأهدافها }
$$

1. أنواع صناديق الثروة السبيادية:

ومن كل ما سبق نستطيع أن نقام مجمو عة أنواية. أنواع للصناديق السبادية بحيث سنركز على معيارين أساسيين هما مصدر أمو الها، و أهدافها. تصنيف صناديق الثروة السيادية حسب مصدر دخلها: يتم تصنيف الصناديق السيادية حسب مصادر دخلها إلى (8)

• الصناديق الممولة عن طريق عوائد المواد الأولية: تقوم الدول المصدرة للمو المباد الأولية وأساسا

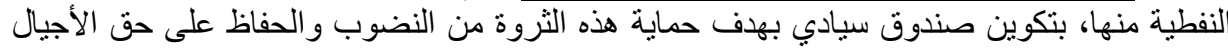

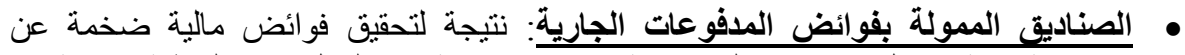

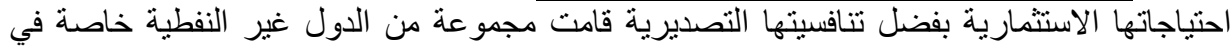

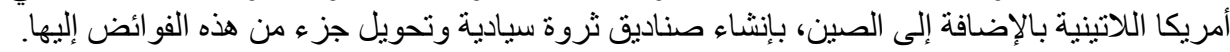

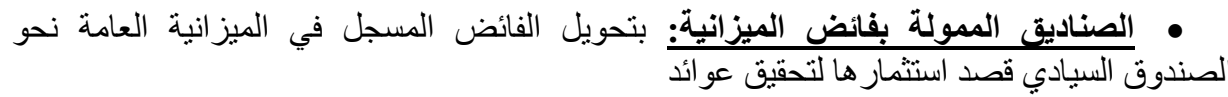

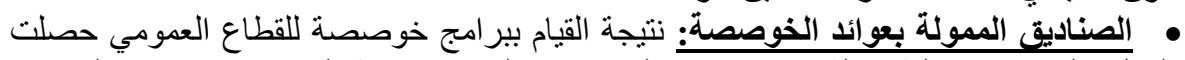

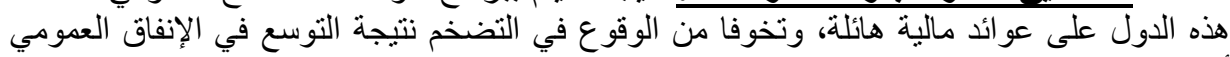

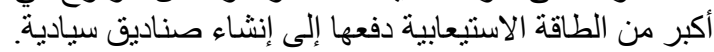

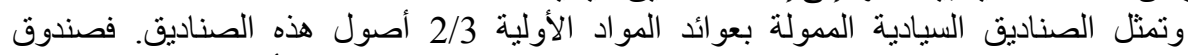

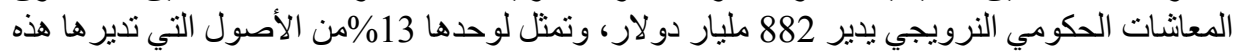

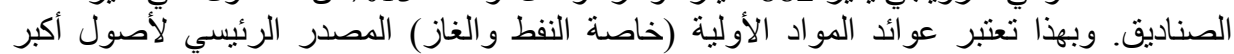


حوكمة صناديق الثروة السيادية وشفافية أعمالها

صناديق الثروة السيادية في العالم في ظل تميز أسعار النفط بالتذبذب. وهو ما يمكن توضيحه في الجدول الجدول رقم(2): تصنيف صناديق الثروة السيادية حسب مصدر دخلها

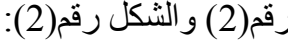

\begin{tabular}{|c|c|c|}
\hline النسبة & قيمة الأصول (مليار دولار) & 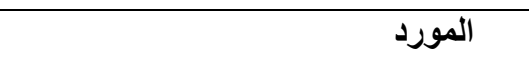 \\
\hline$\% 59.5$ & $4,287.2$ & صناديق الثروة السيادية من المواد الأولية \\
\hline$\% 40.5$ & $2,817.2$ & صناديق الثروة السيادية الأخرى \\
\hline$\% 100$ & $7,104.4$ & المجموع الكلي \\
\hline
\end{tabular}

Source: Fund Rankings, Wealth fund Institute,

"تاريخ الاطلاع "www.swfinstitute.org/fund-rankings/" octobre2014

$.2015 / 04 / 24$

و لتوضيح الإحصاءات الموجودة في الجدول رقم(2) يمكن تمثيلها بيانيا في الثكل رقم(2)

الثكل رقع(2): توزيع صناديق الثروة السيادية حسب مصدر دخلها

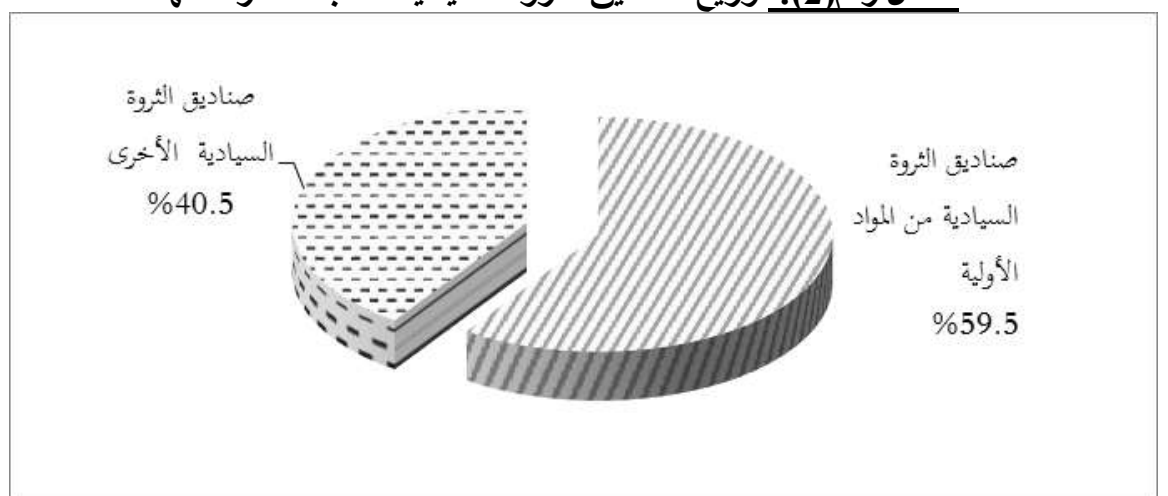

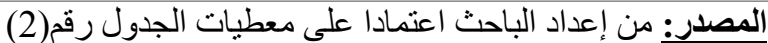

تصنيف صناديق الثروة السيادية حسب الهذف من إنثائها: يصنف صندوف التئ النقد الدولي الصناديق

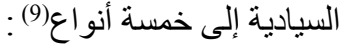

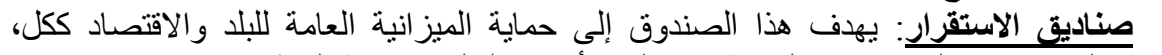

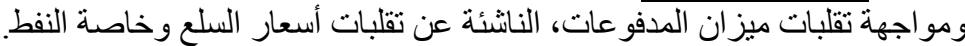

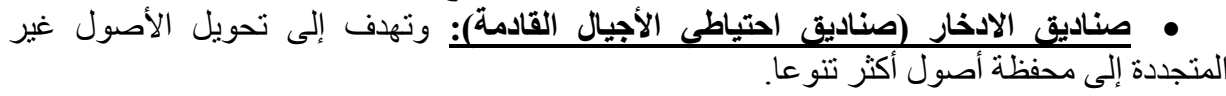

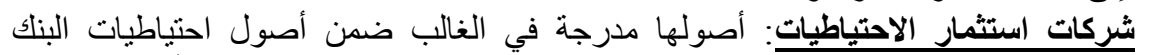

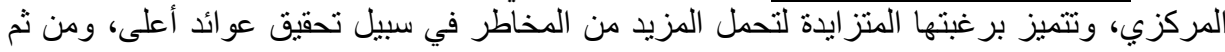
الحد من تكاليف الفرصة البديلة لحيازة الاحتياطات الدولية.

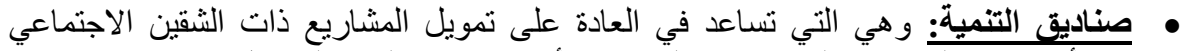

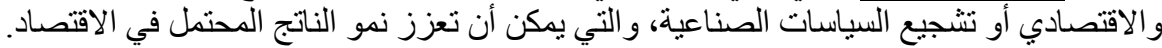

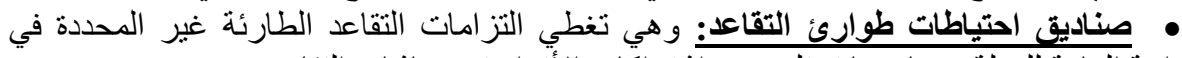

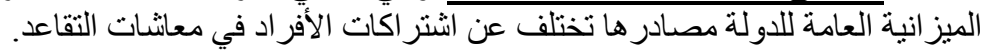


2. أهداف صناديق الثروة السيادية:

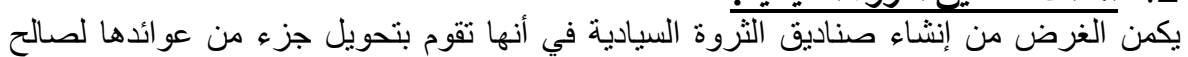

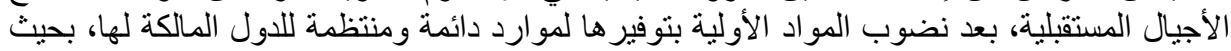

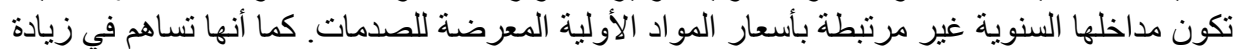

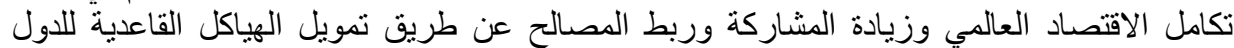

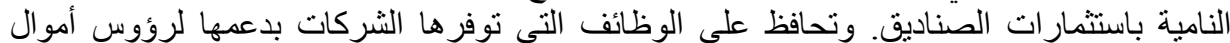

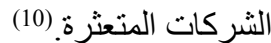

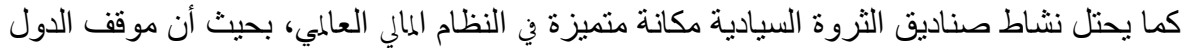

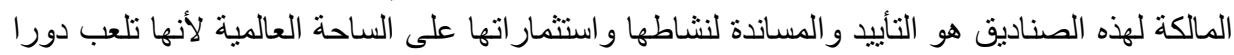

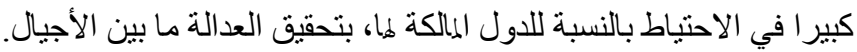

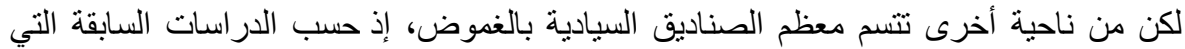

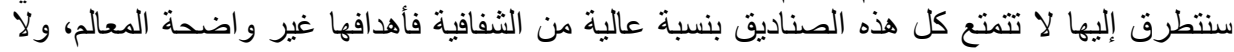

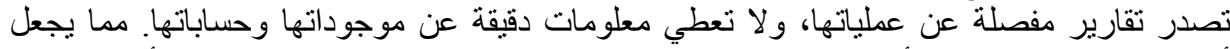

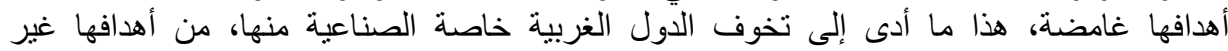

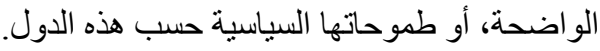

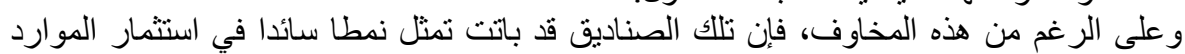

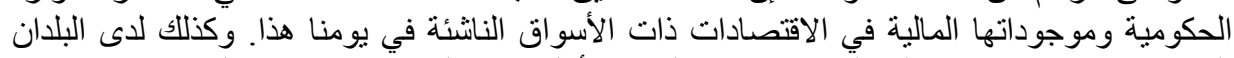

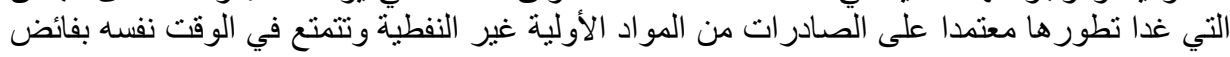

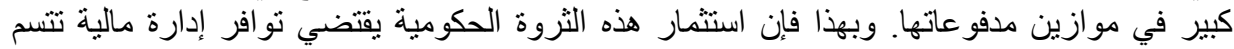

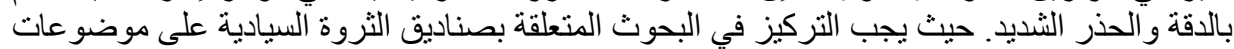

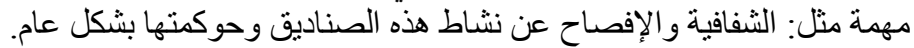

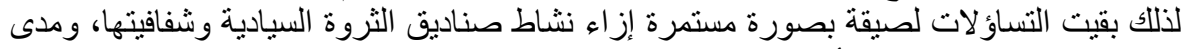

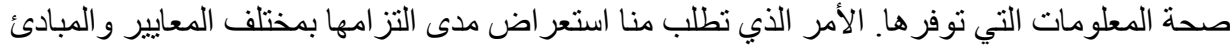
المحددة لثفافية نشاطها اعتمادا على مجموعة الألى من الدراسات والبحات البحوث التي تم الاطلاع عليها في كل مر احل إعداد هذه الورقة البحثية.

\section{المحور الثالث: مدى شفافية نثاطات صناديق الثروة العيادية} 1 1

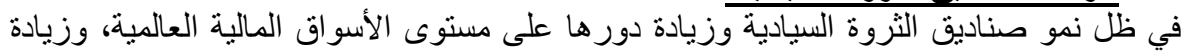

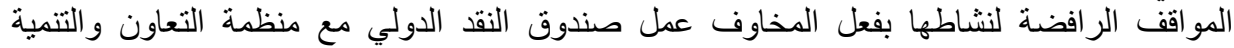

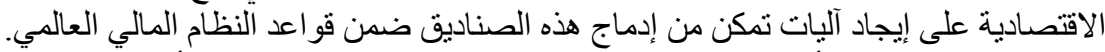

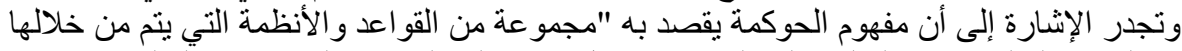

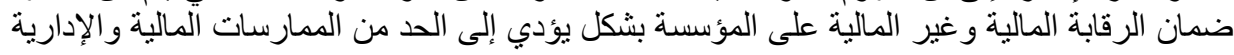

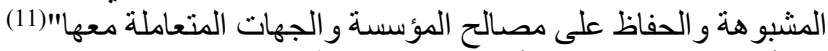

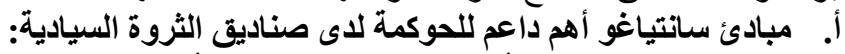

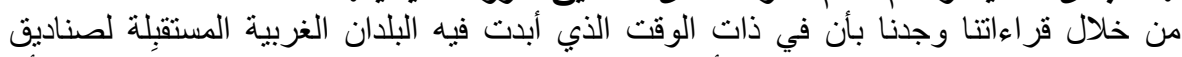

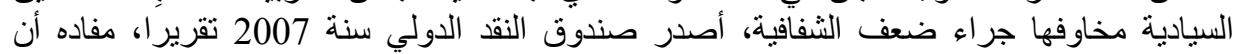

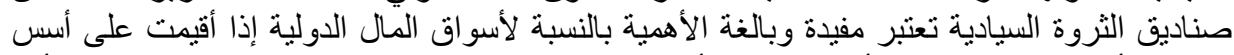

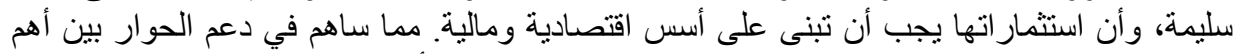

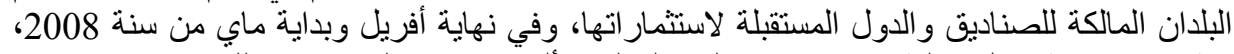

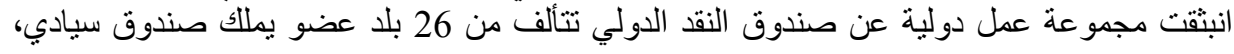


و التي عقدت ثلاثة اجتماعات آخر ها في سانتياغو بالثشيلي، وتمخض عن كل ذلإثك مجمو عة من المبادئ أطلق عليها تسمية "مبادئ سانتياغو"، التي سميت في التئي البدء المبادئ و الممارسات المنعارف عليها (12) (GAPP)

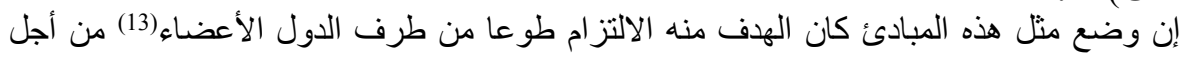

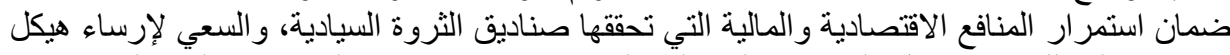

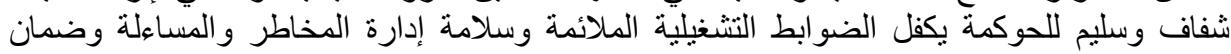

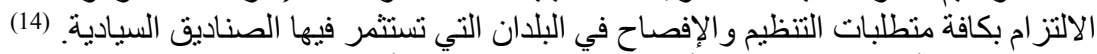

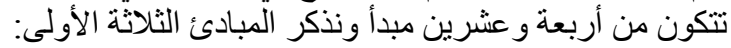

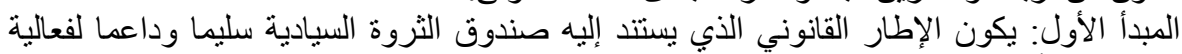

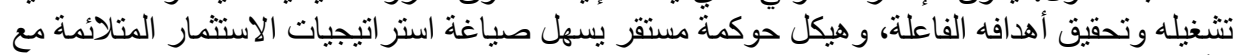

المبدأ الثاني: يتحدد بوضوح الغرض من إنشاء صندوق الثروة السيادية ويتم الإفصاح عنه علنا.

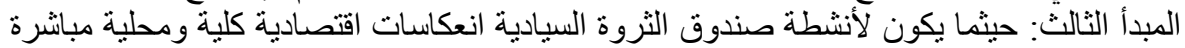

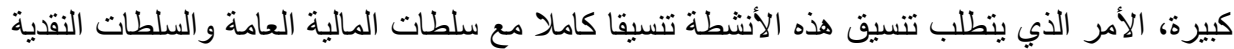
المحلية بغية ضمان الاتساق مع السياسات الاقتصادية الإنية الكلية الثناملة.

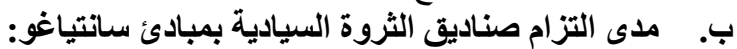

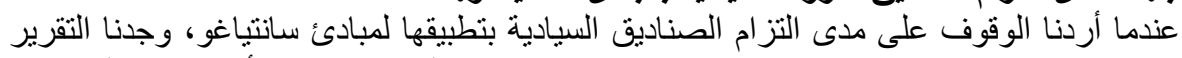

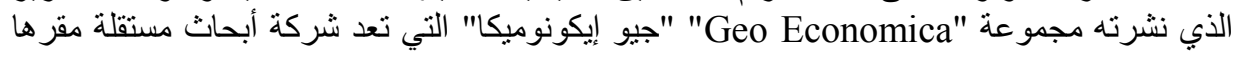
البحث أظهر أن الغالبية بين أكبر صناديق الثروة السيادية في العالم تفتقر إلى الثفافية والحوكمة

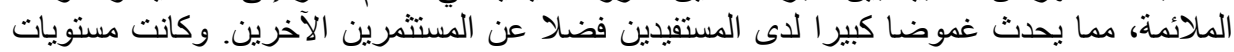

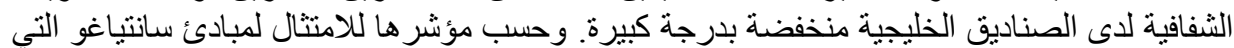

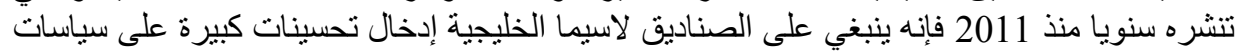
الإفصاح المالي و التحلي بمزيد من الثفافية.

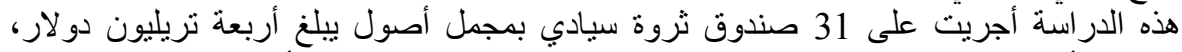

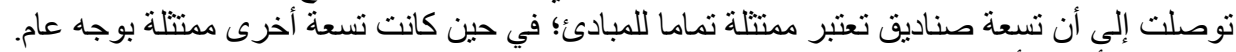

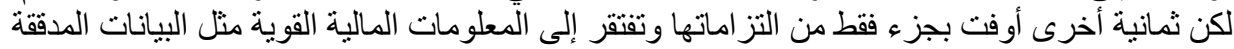

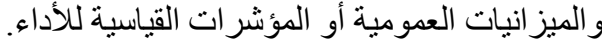

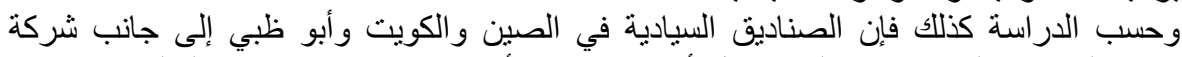

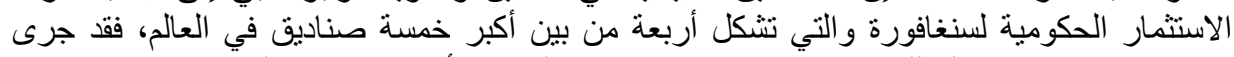

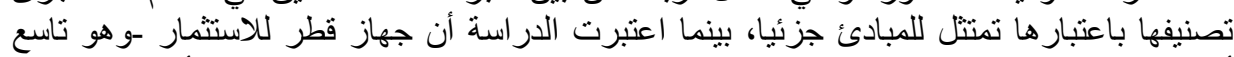

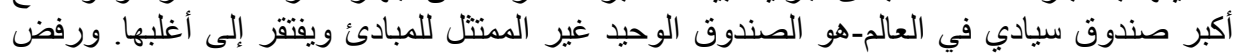
الصندوق التعليق على التنائج. وتعذر تصنيف أربعة صناديق أخرى نظر الخضو عها لتغييرات واسعة و افتقار ها إلى اتجاه بحدد

أما صندوق معاشات التقاعد الحكومي النرويجي وهو أكبر الصناديق السيادية في العالم إذ بيلغ

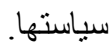

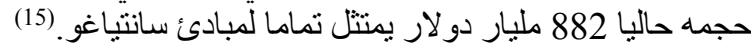

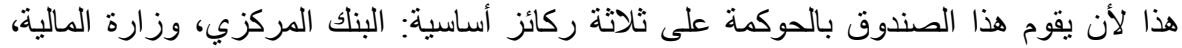

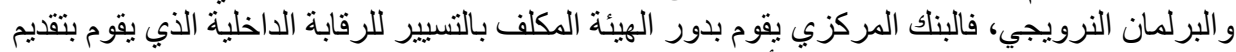

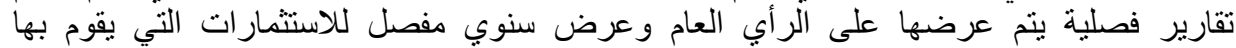

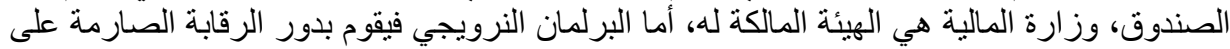
من خلال التقارير الدورية المقدمة له من وزارة المالية. 


\section{Truman مؤشر ترومان}

وفي سياق دراسة حوكمة الصناديق السيادية مدى شفافية أعمالها لا يمكن إهمال مؤشر ترومان،

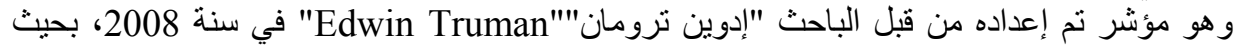

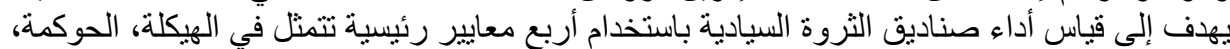

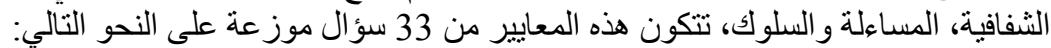

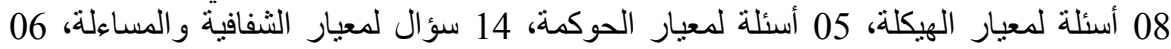
أسئلة لمعيار السلوك، حيث يتألف سلم التتقيط الخاص بالمؤشر من 33 نقطة بمعنى أن الإجابة عن كل

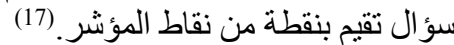

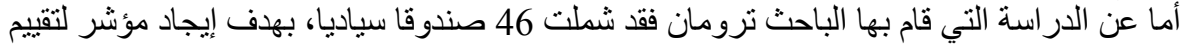

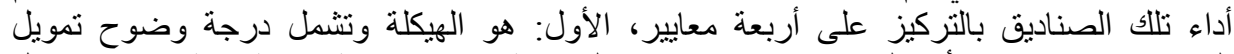

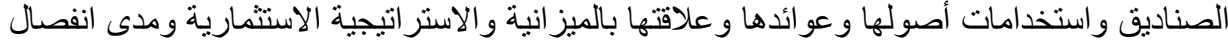

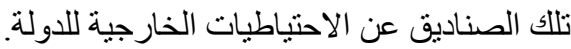

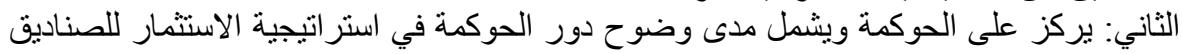

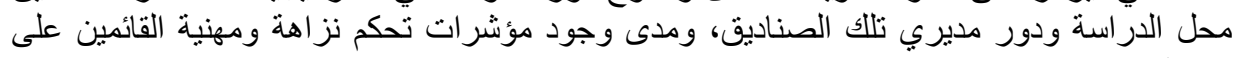

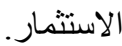

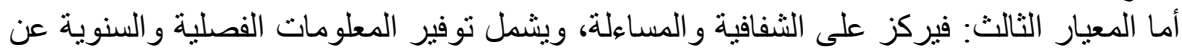

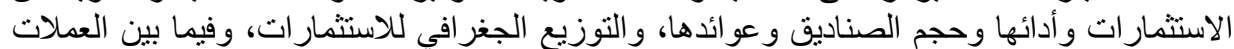

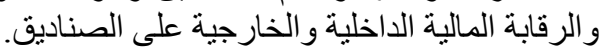

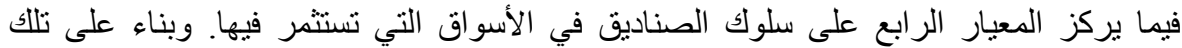

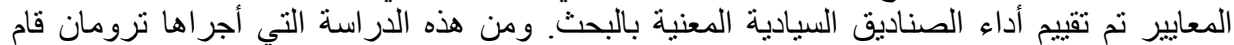

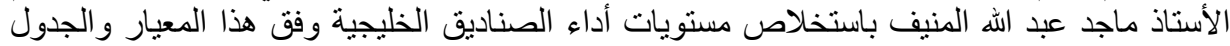

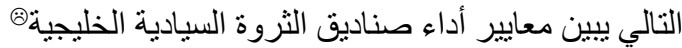

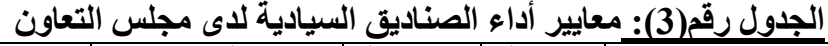

\begin{tabular}{|c|c|c|c|c|c|}
\hline التقييم العام & السلوك & والمساولية & الحوكمة & الهيكلة - الهي & \\
\hline 15.75 & صفر & 5.75 & 4 & 6 & هيئة الاستثمار الكويتية \\
\hline 3.0 & صفر & 0.25 & صفر & 2.75 & هيئة الاستثمار القطرية \\
\hline 3.0 & 0.5 & 0.5 & صفر & 2 & هيئة أبو ظبي للاستثمار \\
\hline 6.5 & صفر & 2.5 & صفر & 4 & صندوق الاحتياطي العام في عمان \\
\hline 15.1 & 1.5 & 6.2 & 2 & 5.4 & متوسط أداء الصناديق السيادية \\
\hline 30.5 & 4 & 14 & 5 & 7.5 & صندوق التقاعد الحكومي للنرويج \\
\hline
\end{tabular}

المصدر: ماجد عبد الله المنيف، صناديق الثروة السيادية ودور ها في إدارة الفو ائض المالية، جامعة الملك

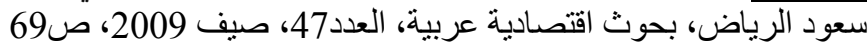

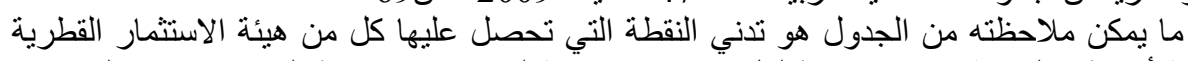

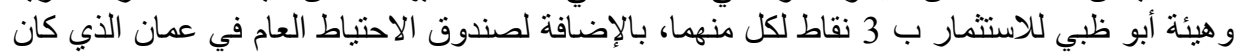


أحسن مقارنة بهما بحيث تحصل على 6.5 نقطة، ولكن تبقى بعيدة عن منوسط أداء صناديق الثروة

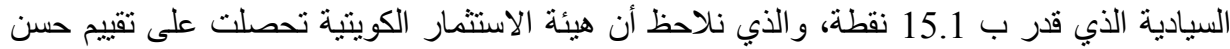

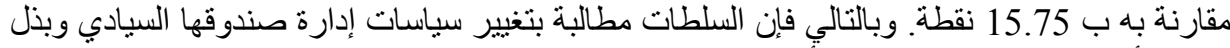

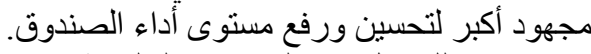

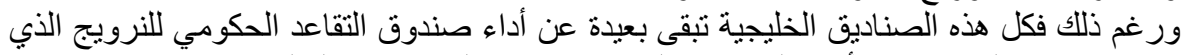
سجل 30.5 نقطة. الذي يعد من أكثر الصناديق السيادية شفافية على مستوى العالم.

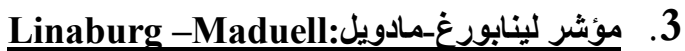

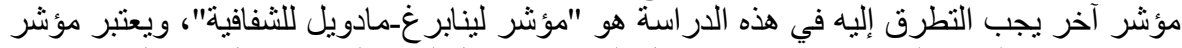

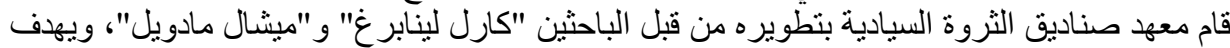

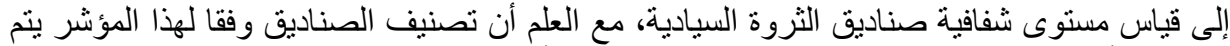

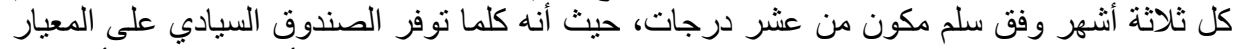

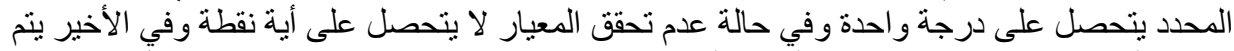

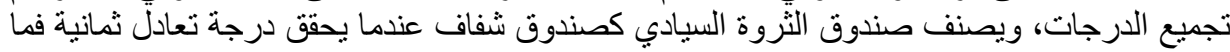

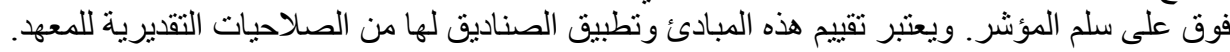
ويمكن توضيح هذه المعايير وفقا للجدول التالي (19):

الجدول رقم(4): مكونات مؤثر لينابرغ-مادويل

\begin{tabular}{|c|c|}
\hline 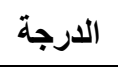 & المعيار \\
\hline $1+$ & توفر معلومات حول هدف الصندوق، موارد الصندوق، هيكل الصندوق \\
\hline $1+$ & توفر تقارير دورية وسنوية مستقلة حول أداء الصندوق \\
\hline $1+$ & توفر معلومات حول أماكن استثمارات الصندوق ونسب المشاركة في الثركات \\
\hline $1+$ & الممنوحة للإطارات المشرفة علول القيمة الإجمالية لمحفظة الصندوق، العوائد المحققة، والتعويضات \\
\hline $1+$ & توفر معلومات حول المبادئ والمراجع المعتمدة من قبل الصندوق. \\
\hline $1+$ & توفر الصندوق على استراتيجيات استثمار وأهداف واضحة. \\
\hline $1+$ & توفر معلومات حول فروع الصندوق والاتصالات الخارجية للصندوق. \\
\hline $1+$ & توفر معلومات حول الهيئات الأجنبية المكلفة بإدارة استثمارات الصندوق \\
\hline $1+$ & توفر الصندوق على موقع الكتروني \\
\hline $1+$ & توفر الصندوق على وسائل الاتصال البريدية والاككترونية \\
\hline
\end{tabular}

Source : http://www.swfinstitute.org/swf-research/linaburg-maduell-

transparency-index-released

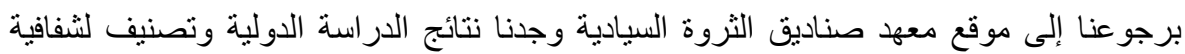

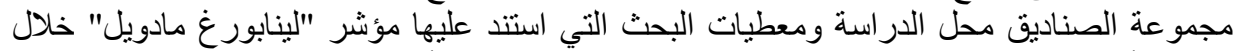
الربع الأول من سنة 2014، وجاءت الثيلي في مقدمة الترتيب كأحسن دولة الثئ عالمية في هذا المنحى. 
وتحصلت كل من الجزائر وفنزويلا وكيريباتي وموريتانيا وبروناي على نقطة واحدة فقط ضمن قائمة

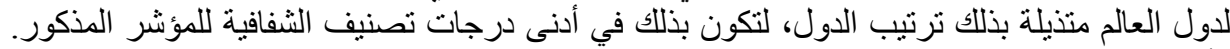

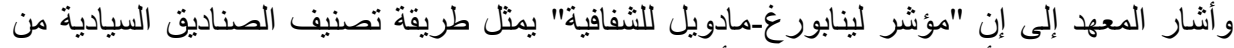

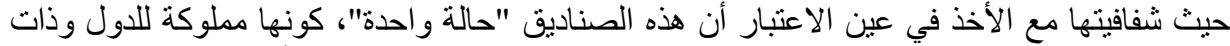

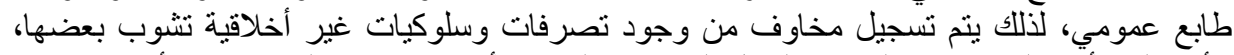

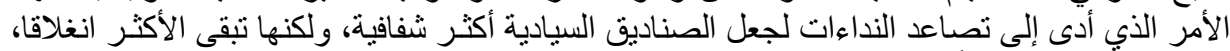

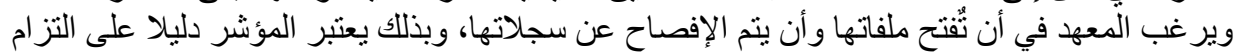
الصناديق بالتعبير عن نو اياها الحقيقية وممار التاتها الاستثمارية.

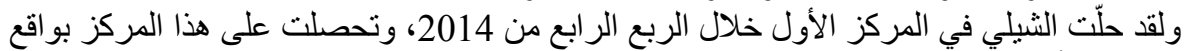

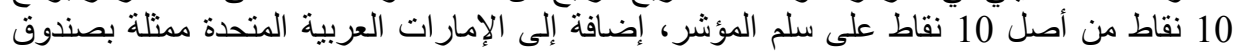

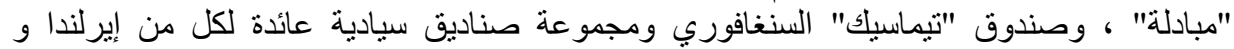

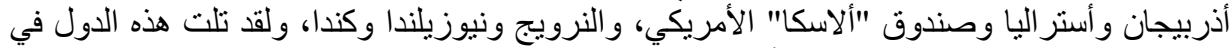

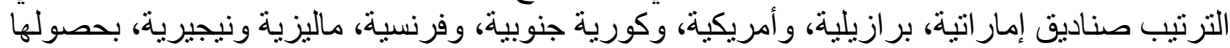

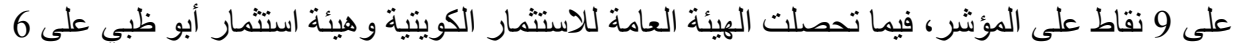
نقاط، وتذيلت الجز ائر و الدول المذكورة معها الترتيب في ذلك التئل

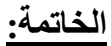

من خلال التطرق لصناديق الثروة السيادية كان بالإمكان معرفة حجم هذه الصناديق، ومكانتها

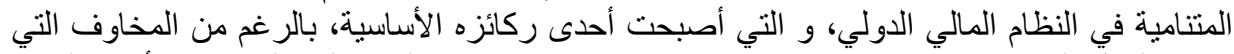

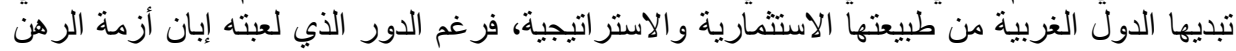

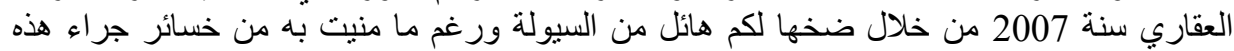

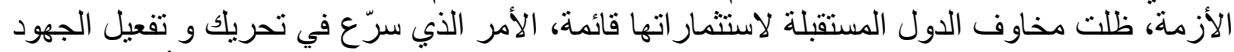

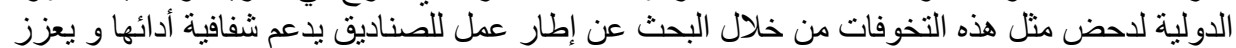

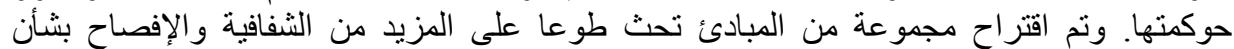

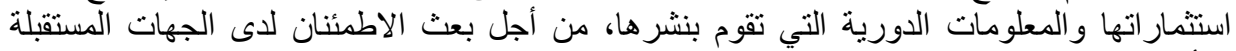

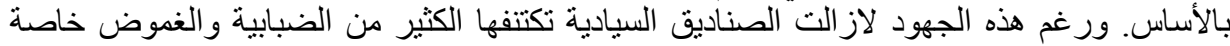
الصناديق الخليجية منها، حيث احتلت مر اكز ذيل التيل الترتيب بكل التئ المؤشرات.

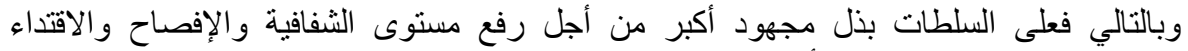
بالصندوق النرويجي الذي يعتبر أكثر الصناديق السيادية شفافية على المستوى العالمي مضافا إليه صندوق "مبادلة" الإمارات العربية المتحدة من خلال:

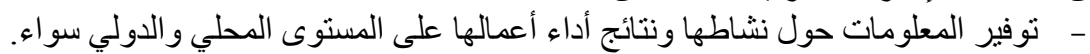

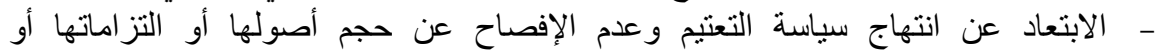
استر اتيجياتها الاستثمارية.

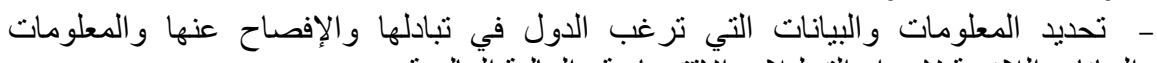
و البيانات اللازمة لإجر اء التحليلات الإقتصادية و المالية العالمية.

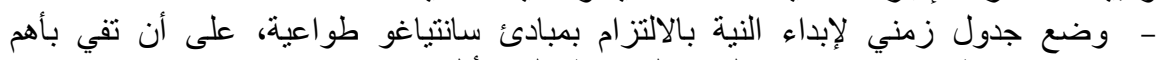

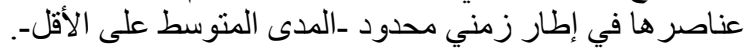

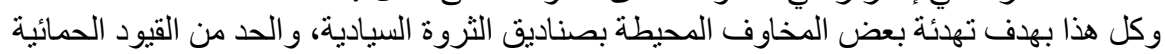

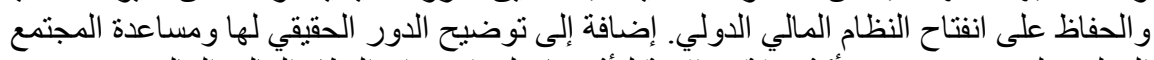

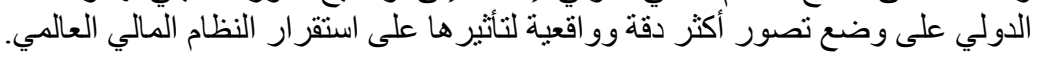

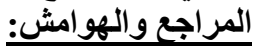

1-صناديق الثروة السيادية، المبادئو والممارسات المنعارف عليها، مجمو عة العمل الدولية لصناديق

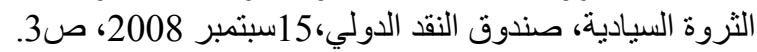


2-Demarolle Alain, « Rapport sue les fonds souverains », la Documentation française, 2008, p4.

3- Sovereign Wealth Funds Institute، what is a Sovereign Wealth Fund، www.swfinstitute.org/sovereign-wealth-fund/,19/01/2014

4- Trésor- ECO. Les conditions d'une contribution positive des fonds souverains à l'économie mondiale, République Française, Janvier $2008, \mathrm{n}^{\circ} 28, \mathrm{P} 1$.

$$
\begin{aligned}
& \text { 5-سليمان ناصر، عو اطف محسن، هل تنشئ الجز ار صندوقا سياديا في في ظل تداعيات الأزمة المالية }
\end{aligned}
$$

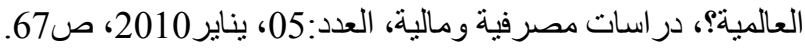

6- http://www.swfinstitute.org/fund-rankings/

7-http://www.swfinstitute.org/fund-rankings/

8- Jaquet Pierre، Les fonds souverains، acteurs du développement ? Cercle des économistes, Contribution au cahier sur les fonds souverains.

9-Driss Agardi, «Gouvernement d'entreprise: Réseaux d'administrateurs et investisseurs institutionnels», Thèse de Doctorat Université Toulouse1

Capitole, 26Septembre 2008, P55.

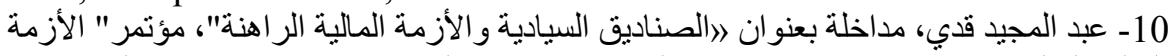

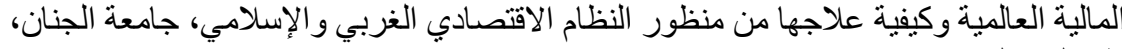

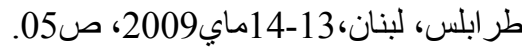

$$
\begin{aligned}
& \text { 11- بوفليح نبيل، دور صناديق الثروة السيادية في تمويل اقتصاديات الدول النفطية، كلية العلوم }
\end{aligned}
$$

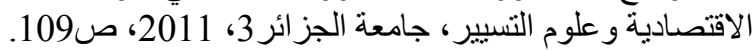

12-GAPP: Generally Accepted Principles and Practice

13- مجمو عة العمل الدولية للصناديق السيادية (IWG)، تقرير مبادئ سانتياغو، 2008، ص3.

www.iwg-swf.org

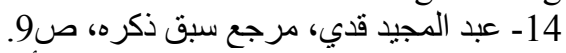

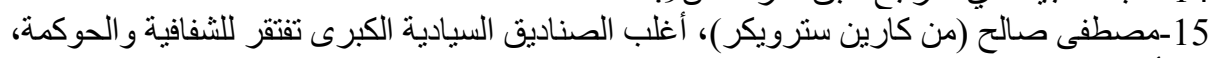

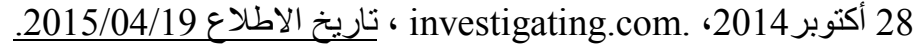

16-Velculescu Delia, «fonds pétrolier norvégien: un exemple pour les fonds souverains», Bulletin d'information du FMI, juillet 2008, p111.

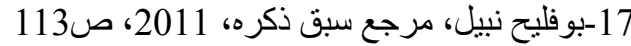

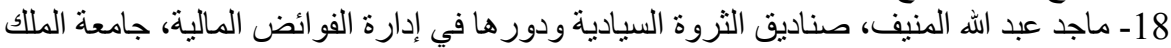

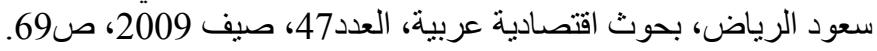

19-Source: http://www.swfinstitute.org/swf-research/linaburg-maduell-

transparency-index-released2015/04/21 تاريخ الاطلاع//20-

20-http://www.swfinstitute.org/swf-article/public-release-4q-2014-linaburg-

maduell-transparency-index-ratings/2015/04/21 تاريخ الاطلاع/20 